\title{
Application of response surface methodological approach to optimise Reactive Black 5 decolouration by crude laccase from Trametes pubescens
}

\author{
Margarida S. Roriz ${ }^{\mathrm{a}, \mathrm{b}}$, Johann F. Osma ${ }^{\mathrm{a}}$, José A. Teixeira ${ }^{\mathrm{b}}$, Susana Rodríguez Couto ${ }^{\mathrm{a}, \mathrm{c}, \mathrm{d}, *}$ \\ a Department of Chemical Engineering, Rovira i Virgili University, Av. Països Catalans 26, 43007 Tarragona, Spain \\ b IBB, Institute for Biotechnology and Bioengineering, Centre of Biological Engineering, University of Minho, Campus de Gualtar, 4710-057 Braga, Portugal \\ c CEIT, Section of Environmental Engineering, Paseo Manuel de Lardizábal 15, 20018 San Sebastian, Spain \\ d Ikerbasque, Basque Foundation for Science, Alameda de Urquijo 36, 48011 Bilbao Spain
}

\section{A R T I C L E I N F O}

Article history:

Received 12 January 2009

Received in revised form 30 March 2009

Accepted 31 March 2009

Available online 8 April 2009

\section{Keywords:}

Laccase

Central composite design

Decolouration

Reactive Black 5

Response surface methodology

\begin{abstract}
A B S T R A C T
Response surface methodology (RSM) was applied to optimise the decolouration of the diazo dye Reactive Black 5 (RB5) by crude laccase from the white-rot fungus Trametes pubescens. The presence of the redox mediator 1-hydroxybenzotriazole (HBT) greatly improved the decolouration levels of RB5 by crude laccase from T. pubescens. Central composite design (CCD) using RSM with three variables namely redox mediator (HBT), dye (RB5) and enzyme (laccase) concentrations was used in this study to optimise significant correlation between the effects of these variables on the decolouration of RB5. The optimum concentrations of HBT, RB5 and laccase were $1.17 \mathrm{mM}, 150 \mathrm{mg} / \mathrm{l}$ and $500 \mathrm{U} / \mathrm{l}$, respectively, for a maximum decolouration of RB5 (about 60\% in $20 \mathrm{~min}$ ). A quadratic model was obtained for dye decolouration through this design. The experimental values were in good agreement with the predicted ones and the model was highly significant, the correlation coefficient being 0.965 . Interaction between HBT and RB5 concentrations, HBT and laccase concentrations and RB5 and laccase concentrations were negligible. In addition, when the kinetic parameters for RB5 decolouration were calculated according to Hannes-Wolf plot, the following values were obtained: $K_{\mathrm{M}}$ of $260.11 \mathrm{mg} / \mathrm{l}$ and $V_{\max } 37.59 \mathrm{mg} / \mathrm{lmin}$.
\end{abstract}

(C) 2009 Elsevier B.V. All rights reserved.

\section{Introduction}

Synthetic dyes are extensively used in the food, cosmetics, plastics and textile industries among others to colour their products. This results in the generation of large amounts of highly polluted effluents. Approximately 10,000 different dyes and pigments are used in textile and printing industries. About $8 \times 10^{5}$ tons of these dyes are produced annually worldwide and at least $10 \%$ of the used dyes are discharged into the environment [1,2]. Azo dyes currently represent about $60 \%$ of the global market for dyes and are widely used in dyeing of textile fibres [3]. The azo dyes are xenobiotic compounds characterised by the presence of one or more azo bonds $(-\mathrm{N}=\mathrm{N}-)$ and aromatic rings [4]. Some of the azo dyes are known to be very toxic and mutagenic to living organisms [5-7]. Therefore, treatment of azo dye-containing wastewater is essential to prevent ecosystem deterioration.

There are several methods used to remove dyes from wastewater. These methods can be chemical, physical or biological. The

\footnotetext{
* Corresponding author at: CEIT, Section of Environmental Engineering, Paseo Manuel de Lardizábal 15, 20018 San Sebastian, Spain. Tel.: +34 943 212800x2239; fax: +34943213076.

E-mail address: srodriguez@ceit.es (S. Rodríguez Couto).
}

physical and chemical methods have high costs, low efficiency and cannot be used with a great variety of dyes. The use of enzymebased methods is a good alternative. The potential advantages of the enzymatic treatments compared to the conventional ones include: application to recalcitrant materials, operation at high and low contaminant concentrations over a wide $\mathrm{pH}$, temperature and salinity range, biomass acclimatization is irrelevant and straight forward process control [8].

The main enzymes involved in the decolouration of dyes are ligninolytic which are produced by white-rot fungi and some litter-decomposing fungi. These include lignin peroxidase (LiP; EC 1.11.1.14), manganese peroxidase (MnP; EC 1.11.1.13) and laccase (p-diphenol: dioxygen oxidoreductase; EC 1.10.3.2). Laccase-based treatments have received much attention for the degradation of different recalcitrant pollutants, as laccase production is constitutive in most white-rot fungi and can be easily enhanced by the addition of different inducers into the culture medium. In addition, in the presence of certain low molecular weight compounds, named redox mediators, laccases are able to oxidise compounds that are not laccase substrates. The redox mediators are readily oxidised by laccases producing, in some cases, very unstable and reactive cationic radicals, which can oxidise more complex substrates before returning to their original state. The electrons taken by laccases are finally transferred back to oxygen to form water 
[9,10]. 1-Hydroxybenzotriazole (HBT) is one of the most efficient laccase mediators but its high cost and potential toxicity are important drawbacks. Therefore, the optimisation of HBT concentration is important for effective decolouration.

Response surface methodology (RSM) is a collection of mathematical and statistical techniques useful for analysing the effects of several independent variables [11]. In many processes, the relationship between the response and independent variables is unknown; therefore the first step in RSM is to approximate the function (response) in terms of analysing the independent variables. Usually, this process employs a low-order polynomial equation in a predetermined region of the independent variables, which will later be analysed to locate the optimum values of independent variables for the optimum response [12].

The aim of the present study was to optimise the decolouration of the recalcitrant diazo dye Reactive Black 5 (RB5) by crude laccase, obtained from cultivation of the white-rot fungus Trametes pubescens, using RSM to optimise the main parameters affecting the decolouration process such as the initial concentrations of enzyme (laccase), dye (RB5) and redox mediator (HBT). The kinetic parameters ( $K_{\mathrm{M}}$ and $\left.V_{\max }\right)$ of the RB5 decolouration by laccase were also determined.

\section{Methods}

\subsection{Laccase production and crude laccase preparation}

The white-rot fungus T. pubescens (MB 89; Institute of Applied Microbiology, University of Natural Resources and Applied Life Sciences, Vienna, Austria) was selected to perform the present study because it has been described as an outstanding laccase producer $[13,14]$. Laccase was produced under semi-solid-state fermentation conditions using dyed sunflower seed shells as support-substrates as described in Rodríguez Couto et al. [15] because this approach allowed the production of high titres of laccase as the only ligninolytic enzyme.

Culture broth was recovered at the maximum laccase activity (day 10), filtered, clarified by centrifugation at $8000 \times \mathrm{g}$ for $15 \mathrm{~min}$, frozen, defrosted and, then, filtered to remove the precipitated polysaccharides. The resulting clear filtrate was concentrated on an Amicon membrane with a molecular cut-off of $10 \mathrm{kDa}$. The experiments were performed with this concentrated clear filtrate.

\subsection{Determination of laccase activity}

ABTS was used as a substrate for the spectrophotometric determination of laccase activity as described by Niku-Paavola et al. [16]. One activity unit (U) was defined as the amount of enzyme that oxidised $1 \mu \mathrm{mol}$ of ABTS per min. The activities were expressed in $\mathrm{U} / 1$.

\subsection{Experimental procedure}

The dye used was the recalcitrant diazo dye Reactive Black 5 (RB5) purchased from Sigma-Aldrich (St. Louis, MO, USA). RB5 was chosen because it is inexpensive and one of the most widely used dyes in the textile industry [17]. Stock solutions $(0.1 \% \mathrm{w} / \mathrm{v}$ in water) were stored in the dark at room temperature and the desired concentrations of the dye were obtained by further dilutions. The reaction mixtures contained citrate phosphate buffer ( $\mathrm{pH} 4.0)$, different concentrations of crude laccase, redox mediator (HBT) and dye (RB5) in a final volume of $5 \mathrm{ml}$. All the reactions were incubated at room temperature, without shaking and in darkness. The residual dye concentration was spectrophotometrically measured from 400 to $800 \mathrm{~nm}$ and calculated by measuring the area under the plot. This approach takes into account the conversion of the dye
Table 1

The range and the levels of the variables.

\begin{tabular}{lllcccrcr}
\hline Factor & Variable & Unit & \multicolumn{5}{c}{ Range and level of actual and coded values } \\
\cline { 4 - 8 } & & & $-\alpha$ & -1 & 0 & 1 & $\alpha$ \\
\hline$X_{1}$ & HBT & $\mathrm{mM}$ & 0.33 & 0.5 & 0.75 & 1 & 1.17 \\
$X_{2}$ & Dye & $\mathrm{mg} / \mathrm{l}$ & 65.9 & 100 & 150 & 200 & 234.1 \\
$X_{3}$ & Enzyme & $\mathrm{U} / \mathrm{l}$ & 163.6 & 300 & 500 & 700 & 836.4 \\
\hline
\end{tabular}

molecules to other compounds absorbing at different wavelengths and then, the ratio of the area under the visible spectrum is always equal to or lower than the ratio of the absorbances at the peak. A UV-visible spectrophotometer (Thermo Spectronic, model Helios alfa, Cambridge, UK) was used in all the experiments.

Dye decolouration was calculated by means of the formula:

$D=\frac{\left(A_{\text {ini }}-A_{\text {obs }}\right)}{A_{\text {ini }}} \times 100$

where $D$ is the decolouration of RB5 (in \%), $A_{\text {ini }}$ is the area under the curve of the absorption spectrum from 400 to $800 \mathrm{~nm}$ at time zero and $A_{\text {obs }}$ is the area under the curve of the absorption spectrum from 400 to $800 \mathrm{~nm}$ at a determined time.

Samples were diluted prior to measurement in order that the absorbance showed values below 1, and hence that the LambertBeer law could be applied. A control test containing the same amount of a heat-denatured laccase was also performed in parallel.

\subsection{Response surface methodology and central composite design}

Since the conventional method of optimisation, "one factor at a time" approach is laborious, time consuming and incomplete, response surface methodology (RSM) using central composite design (CCD) was applied to model the decolouration process. This approach involves full factorial search by examining simultaneous, systematic and efficient variation of important components, identifying possible interactions, higher order effects and determining the optimum operational conditions. However, RSM using CCD is useful for a small number of variables (up to five) but it is impractical for a large number of variables due to the high number of experimental runs required [18].

To explore the effect of variables on the response in the region of investigation, a CCD with three variables at three levels was performed. HBT, RB5 and laccase concentrations were considered the most effective independent variables according to previous experiments $[19,20]$. The percentage of RB5 decolouration was taken as the response. The CCD was applied using Design Expert software (Stat Ease, 7.1 trial version). The range and the levels of the variables under investigation in this study are given in Table 1.

In the regression equation, the test variables were coded according to the equation:

$\mathbf{X}_{i}=\frac{X_{i}-X_{i}^{0}}{\Delta X_{i}}$

where $\mathbf{X}_{i}$ is the independent variable coded value, $X_{i}$ is the independent variable real value, $X_{i}^{0}$ is the independent variable real value on the centre point [21] and $\Delta X_{i}$ is the interval, $i=1,2,3$.

The response was related to the selected variables by a quadratic model as follows:

$$
\begin{aligned}
Y= & \beta_{0}+\beta_{1} X_{1}+\beta_{2} X_{2}+\beta_{3} X_{3}+\beta_{11} X_{1}^{2}+\beta_{22} X_{2}^{2}+\beta_{33} X_{3}^{2}+\beta_{1} \beta_{2} X_{1} X_{2} \\
& +\beta_{1} \beta_{3} X_{1} X_{3}+\beta_{2} \beta_{3} X_{2} X_{3}
\end{aligned}
$$

where $Y$ is the predicted response; $\beta_{0}$ is a constant coefficient; $\beta_{1}$, $\beta_{2}, \beta_{3}$ are the linear coefficients; $\beta_{11}, \beta_{22}, \beta_{33}$ are the quadratic coefficients; $\beta_{1} \beta_{2}, \beta_{1} \beta_{3}, \beta_{2} \beta_{3}$ are the interactions of the coefficients and $X_{1}, X_{2}, X_{3}$ are the coded factors. 
Table 2

Experimental conditions of CCD runs of Design Expert 7.1.

\begin{tabular}{|c|c|c|c|c|c|c|}
\hline \multirow[t]{2}{*}{ Run } & \multicolumn{3}{|c|}{ Coded values } & \multicolumn{3}{|c|}{ Actual values } \\
\hline & $X_{1}$ & $X_{2}$ & $X_{3}$ & $\mathrm{HBT}(\mathrm{mM})$ & Dye $(\mathrm{mg} / \mathrm{l})$ & Laccase (U/l) \\
\hline 1 & -1 & -1 & -1 & 0.5 & 100 & 300 \\
\hline 2 & 1 & -1 & -1 & 1 & 100 & 300 \\
\hline 3 & -1 & 1 & -1 & 0.5 & 200 & 300 \\
\hline 4 & 1 & 1 & -1 & 1 & 200 & 300 \\
\hline 5 & -1 & -1 & 1 & 0.5 & 100 & 700 \\
\hline 6 & 1 & -1 & 1 & 1 & 100 & 700 \\
\hline 7 & -1 & 1 & 1 & 0.5 & 200 & 700 \\
\hline 8 & 1 & 1 & 1 & 1 & 200 & 700 \\
\hline 9 & -1.68 & 0 & 0 & 0.33 & 150 & 500 \\
\hline 10 & 1.68 & 0 & 0 & 1.17 & 150 & 500 \\
\hline 11 & 0 & -1.68 & 0 & 0.75 & 65.9 & 500 \\
\hline 12 & 0 & 1.68 & 0 & 0.75 & 234.1 & 500 \\
\hline 13 & 0 & 0 & -1.68 & 0.75 & 150 & 163.6 \\
\hline 14 & 0 & 0 & 1.68 & 0.75 & 150 & 836.4 \\
\hline 15 & 0 & 0 & 0 & 0.75 & 150 & 500 \\
\hline 16 & 0 & 0 & 0 & 0.75 & 150 & 500 \\
\hline 17 & 0 & 0 & 0 & 0.75 & 150 & 500 \\
\hline 18 & 0 & 0 & 0 & 0.75 & 150 & 500 \\
\hline 19 & 0 & 0 & 0 & 0.75 & 150 & 500 \\
\hline 20 & 0 & 0 & 0 & 0.75 & 150 & 500 \\
\hline
\end{tabular}

Three important parameters: concentration of HBT $\left(X_{1}\right)$, concentration of RB5 $\left(X_{2}\right)$ and concentration of laccase $\left(X_{3}\right)$ were selected as the independent variables and the decolouration percentage $(Y)$ was the dependent response variable. Each of the independent variables was studied at five different levels containing two star points $(\alpha=1.68)$ and six replications of the central point with a total of 20 experiments. Percentage of RB5 decolouration corresponding to combined effects of the three variables was studied in their specified ranges, HBT concentration: $0.33-1.17 \mathrm{mM}$, RB5 concentration: 65.9-234.1 mg/l and laccase concentration: 163.6-836.4 U/l. The other two process variables, $\mathrm{pH}$ and temperature were kept constant at 4 and $25^{\circ} \mathrm{C}$, respectively throughout the 20 experiments. The plan of CCD in coded levels of the three independent variables is shown in Table 2.

\subsection{Software and data analysis}

The results of the experimental design were analysed and interpreted using Design Expert software(Stat Ease, 7.1 trial version). The response 3D plots were built using Sigma Plot software 7.1 (Jandel Scientific).

\subsection{Kinetic study}

Substrate specificity towards the dye RB5 was analysed kinetically at room temperature. The reaction mixtures consisted of RB5 solution (at varying concentrations ranging from 50 to $300 \mathrm{mg} / \mathrm{l}$ ), laccase $(700 \mathrm{U} / \mathrm{l})$ and $\mathrm{HBT}(1.17 \mathrm{mM})$ in citrate phosphate buffer $(\mathrm{pH}$ 4.0 ) in a final volume of $5 \mathrm{ml}$. All the reactions were incubated at room temperature $\left(25^{\circ} \mathrm{C}\right)$, without shaking and in complete darkness. Decolouration was spectrophotometrically monitored as described in Section 2.3.

\section{Results and discussion}

\subsection{Optimisation of RB5 decolouration using RSM}

The first step in this study was the identification of the variables that affected decolouration and their range. Thus, initially, we tested the capacity of the crude laccase alone in the decolouration of RB5 at pHs 4 and 5. It was found that the laccase was only able to decolourise the dye RB5 at pH 4 and the decolouration obtained was very low (10\% in $24 \mathrm{~h}$ ). Further, the decolouration

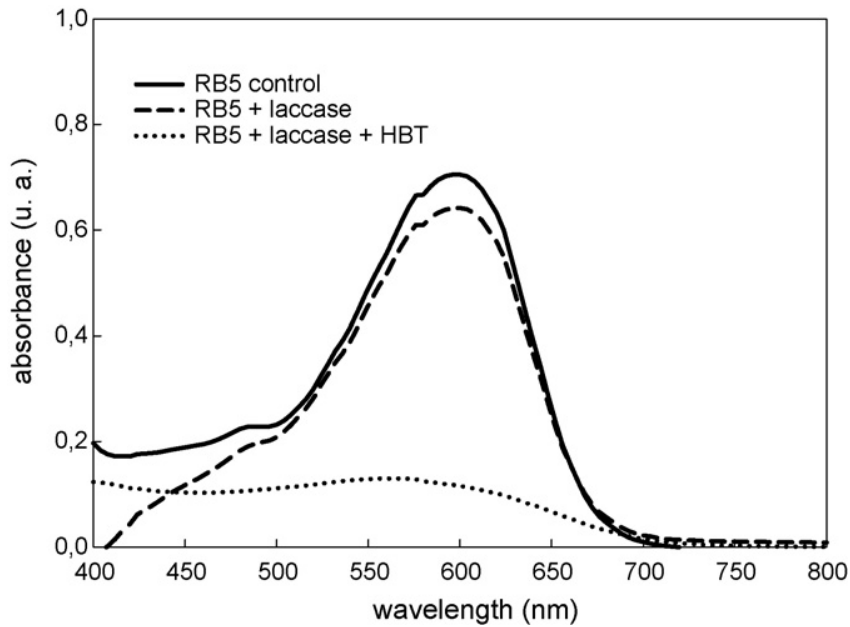

Fig. 1. UV-vis absorption spectrum of Reactive Black 5 (RB5) decolouration by crude laccase of Trametes pubescens. Spectrum obtained from RB5 $(150 \mathrm{mg} / \mathrm{l})$ treated by crude laccase $(500 \mathrm{U} / \mathrm{l})$ with and without $0.75 \mathrm{mM}$ 1-hydroxybenzotriazole incubated for $24 \mathrm{~h}$.

of RB5 by crude laccase in the presence of the redox mediator 1hydroxybenzotriazole (HBT) was studied and was found that HBT had an immediate effect on RB5 decolouration by laccase. As shown in Fig. 1 laccase hardly decolourised the dye RB5 in the absence of HBT. This result is in agreement with those obtained by other researchers [22-27]. Although the redox mediators are effective in some circumstances, over certain concentration they inhibit the laccase activity [28]. Therefore, optimisation of HBT concentration is essential for a successful decolouration. In addition, enzyme and dye concentrations were also selected as variables.

The experimental results were analysed through RSM to obtain an empirical model for the best response. The actual and the predicted dye decolouration percentages are shown in Table 3. Actual values correspond to the measured response data for a particular run and the predicted values were evaluated from the model. The quadratic model was used to explain the mathematical relationship between the independent variables and the dependent response. The mathematical expression of the relationship to RB5 decolouration with the variables $X_{1}, X_{2}$ and $X_{3}$ is shown below in terms of

Table 3

The actual and the predicted dye decolouration percentage.

\begin{tabular}{rlrr}
\hline Run & Response & & $R$-studentised residual \\
\cline { 2 - 3 } & Observed & Predicted & \\
\hline 1 & 28.48 & 24.12 & 1.581 \\
2 & 50.02 & 48.17 & 0.619 \\
3 & 11.52 & 7.96 & 1.251 \\
4 & 30.80 & 32.01 & -0.401 \\
5 & 44.69 & 41.93 & 0.944 \\
6 & 62.15 & 65.98 & -1.359 \\
7 & 22.91 & 25.76 & -0.979 \\
8 & 52.16 & 49.82 & 0.794 \\
9 & 14.22 & 18.03 & -1.931 \\
10 & 59.83 & 58.48 & 0.604 \\
11 & 46.59 & 48.80 & -1.018 \\
12 & 21.35 & 21.61 & -0.114 \\
13 & 19.68 & 23.93 & -2.237 \\
14 & 55.66 & 53.88 & 0.809 \\
15 & 48.50 & 45.47 & 0.954 \\
16 & 44.68 & 45.47 & -0.240 \\
17 & 42.64 & 45.47 & -0.887 \\
18 & 42 & 45.47 & -1.105 \\
19 & 48.52 & 45.47 & 0.961 \\
20 & 46.9 & 45.47 & 0.438 \\
\hline & & & \\
\hline
\end{tabular}


Table 4

ANOVA results for the equation of Design Expert 7.1.

\begin{tabular}{|c|c|c|c|c|c|}
\hline Source & Sum of squares & Degree of freedom & Mean square & $F$-value & Probability $>F$ \\
\hline Model & 4255.49 & 6 & 709.25 & 59.02 & $<0.0001$ \\
\hline$X_{1}$ & 1975.10 & 1 & 1975.10 & 164.35 & $<0.0001$ \\
\hline$X_{2}$ & 892.43 & 1 & 892.43 & 74.26 & $<0.0001$ \\
\hline$X_{3}$ & 1082.74 & 1 & 1082.74 & 90.10 & $<0.0001$ \\
\hline$X_{1}^{2}$ & 93.67 & 1 & 93.67 & 7.79 & 0.0153 \\
\hline$X_{2}^{2}$ & 189.85 & 1 & 189.85 & 15.80 & 0.0016 \\
\hline$X_{3}^{2}$ & 77.66 & 1 & 77.66 & 6.46 & 0.0246 \\
\hline Residual & 156.23 & 13 & 12.02 & & \\
\hline Lack of fit & 115.05 & 8 & 14.38 & 1.75 & 0.2794 \\
\hline Pure error & 41.17 & 5 & 8.23 & & \\
\hline Total & 4411.72 & 19 & & & \\
\hline$R$-squared & 0.9646 & Adj $R$-squared & 0.9482 & & \\
\hline
\end{tabular}

Table 5

Decolouration percentages of Reactive Black 5 (RB5) reported by different authors for different RB5, laccase and 1-hydroxybenzotriazole concentrations.

\begin{tabular}{|c|c|c|c|c|c|}
\hline Laccase source & [RB5] (mg/l) & {$[\mathrm{HBT}](\mathrm{mM})$} & [laccase] (U/1) & Decolouration (\%) & Reference \\
\hline P. pinsitus & 200 & 2 & 2400 & $70 \%$ in $16 \mathrm{~h}$ & Claus et al. [22] \\
\hline Trametes modesta & 41.7 & 0.5 & 12 & $88 \%$ in $3 \mathrm{~h}$ & Nyanhongo et al. [23] \\
\hline Picnoporus cinnabarinus & 24.8 & 0.5 & 100 & $50 \%$ in $6 \mathrm{~h}$ & Camarero et al. [24] \\
\hline Pleurotus sajor-caju & 62.5 & 1.5 & 2500 & $84.4 \%$ in $36 \mathrm{~h}$ & Murugesan et al. [26] \\
\hline Ischnoderma resinosum & 100 & 5 & 25 & $70 \%$ in $1 \mathrm{~h}$ & Kokol et al. [27] \\
\hline T. pubescens & 150 & 1.17 & 500 & $60 \%$ in $20 \mathrm{~min}$ & This study \\
\hline
\end{tabular}

coded factors:

$$
\begin{aligned}
Y= & 45.47+12.03 \cdot X_{1}-8.08 \cdot X_{2}+8.90 \cdot X_{3}+1.19 \cdot X_{1} \cdot X_{2} \\
& +0.74 \cdot X_{1} \cdot X_{3}+0.55 \cdot X_{2} \cdot X_{3}-2.55 \cdot X_{1}^{2}-3.63 \cdot X_{2}^{2}-2.32 \cdot X_{3}^{2}
\end{aligned}
$$

Statistical analysis showed that the coefficients $X_{1} \cdot X_{2}, X_{1} \cdot X_{3}$ and $X_{2} \cdot X_{3}$ were statistically insignificant, being deleted from the equation and added to the lack of fit. As a result, a new regression model was obtained:

$$
\begin{aligned}
Y= & 45.47+1203 \cdot X_{1}-8.08 \cdot X_{2}+8.90 \cdot X_{3}-2.55 \cdot X_{1}^{2} \\
& -3.63 \cdot X_{2}^{2}-2.32 \cdot X_{3}^{2}
\end{aligned}
$$

The results of analysis of variance (ANOVA) for Eq. (5) are shown in Table 4 . The model of the equation was significant at the $1 \%$ level and each term was significant at the $5 \%$ level. A coefficient of determination $\left(R^{2}\right)$ value of 0.965 showed that the equation was highly reliable. The model also revealed a statistically insignificant lack of fit $(P=0.279)$ at $5 \%$ level.

The optimum concentrations of HBT, RB5 and laccase were found to be $1.17 \mathrm{mM}, 150 \mathrm{mg} / \mathrm{l}$ and $500 \mathrm{U} / \mathrm{l}$, respectively, for a maximum RB5 decolouration of ca. $60 \%$ in 20 min. The result obtained is similar or even better than those reported by other authors (Table 5).

The effects of variables on RB5 decolouration are shown through Figs. 2-4. All these figures were obtained at a fixed time of decolouration ( $20 \mathrm{~min}$ ) and $\mathrm{pH} 4$. A graph was constructed by plotting the central values of the variables that affect the decolouration ( $500 \mathrm{U} / \mathrm{l}$ of laccase, $0.75 \mathrm{mM}$ HBT and $150 \mathrm{mg} / \mathrm{l} \mathrm{RB} 5$ ). The effect of HBT and enzyme concentrations on the response at a fixed dye concentration of $150 \mathrm{mg} / \mathrm{l}$ is shown in Fig. 2. Increase in both HBT and laccase concentrations yielded an increase in the response surface. The response value reached its highest value at $1.17 \mathrm{mM}$ HBT and 836.4 U/l laccase. It can be observed that increasing HBT and laccase concentrations over the above-mentioned values does not increase RB5 decolouration. In general, in enzymatic reactions the reaction rate increases with the increase in substrate concentration. When the substrate concentration increases to a certain high value, the reaction rate reaches a plateau and keeps constant even if more substrate is used [29].

The effect of HBT and dye concentrations on the response at a fixed laccase concentration of $500 \mathrm{U} / 1$ was shown in Fig. 3. The response plot revealed that with the increase in HBT concentration and decrease in RB5 concentration dye decolouration increased. Maximum RB5 decolouration was attained at $1.17 \mathrm{mM}$ HBT and $65.9 \mathrm{mg} / \mathrm{l} \mathrm{RB} 5$.

The effect of enzyme and dye concentrations at a fixed HBT concentration of $0.75 \mathrm{mM}$ is shown in Fig. 4. The plot shows that RB5 decolouration decreased with increase in RB5 concentration and increased with increase in laccase concentration. Maximum decolouration was obtained at concentrations of RB5 between 100 and $125 \mathrm{mg} / \mathrm{l}$ and concentrations of laccase between 700 and

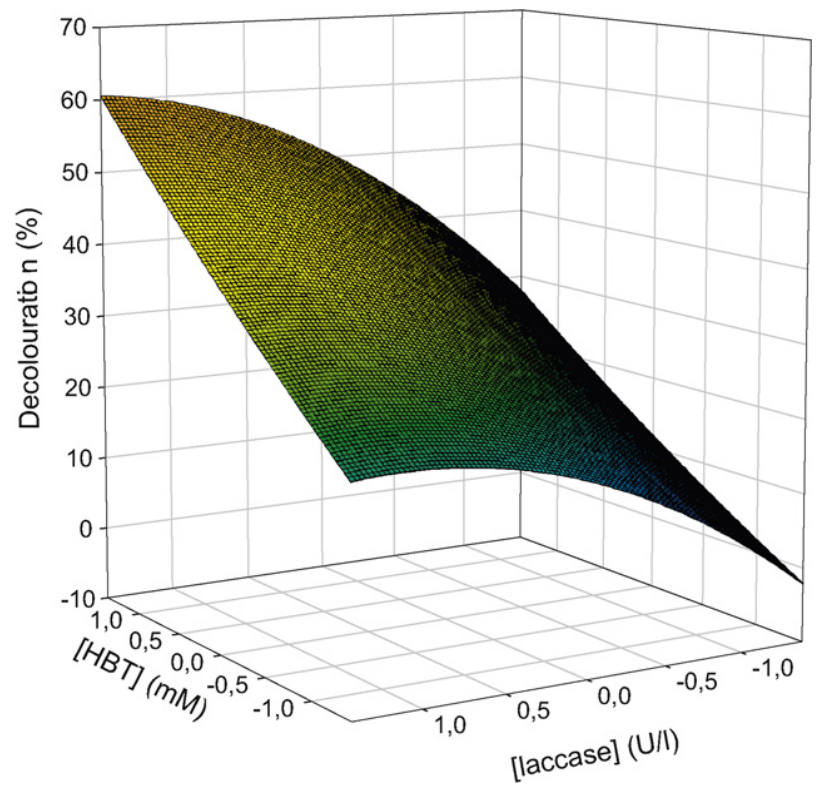

Fig. 2. 3D surface plot for the removal of Reactive Black 5 (RB5) by laccase as a function of 1-hydroxybenzotriazole (HBT) and enzyme concentrations at a fixed value of $150 \mathrm{mg} / \mathrm{l}$ RB5. 


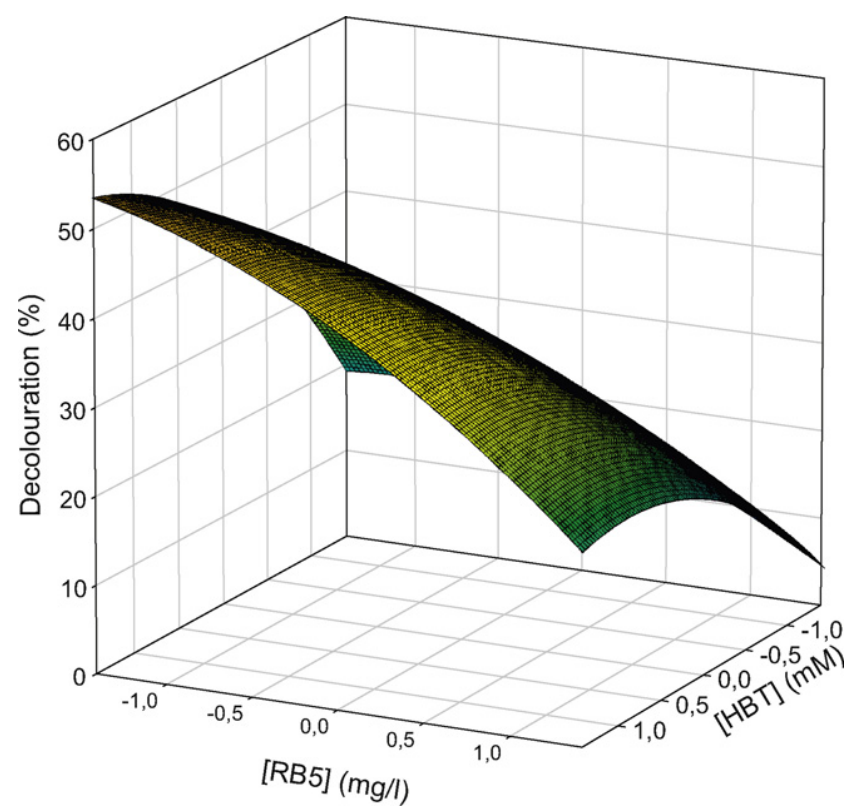

Fig. 3. 3D surface plot for the removal of Reactive Black 5 (RB5) by laccase as a function of 1-hydroxybenzotriazole (HBT) and dye concentrations at a fixed value of $500 \mathrm{U} / 1$ laccase.

$800 \mathrm{U} / \mathrm{l}$. It can be observed that decolouration decreased with increased RB5 concentration even in the presence of high laccase concentrations.

\subsubsection{Adequacy of the model}

Generally, it is important to assess the fitted model to ensure that it gives sufficient approximation of the results obtained in the experimental conditions. A check of the normality assumption can be made by constructing a normal probability plot of the residuals as given in Fig. 5. The normality assumption is satisfied if the residuals plot approximated along a straight line. The coefficient of multiple regression, $R^{2}$, is a global statistic parameter to access

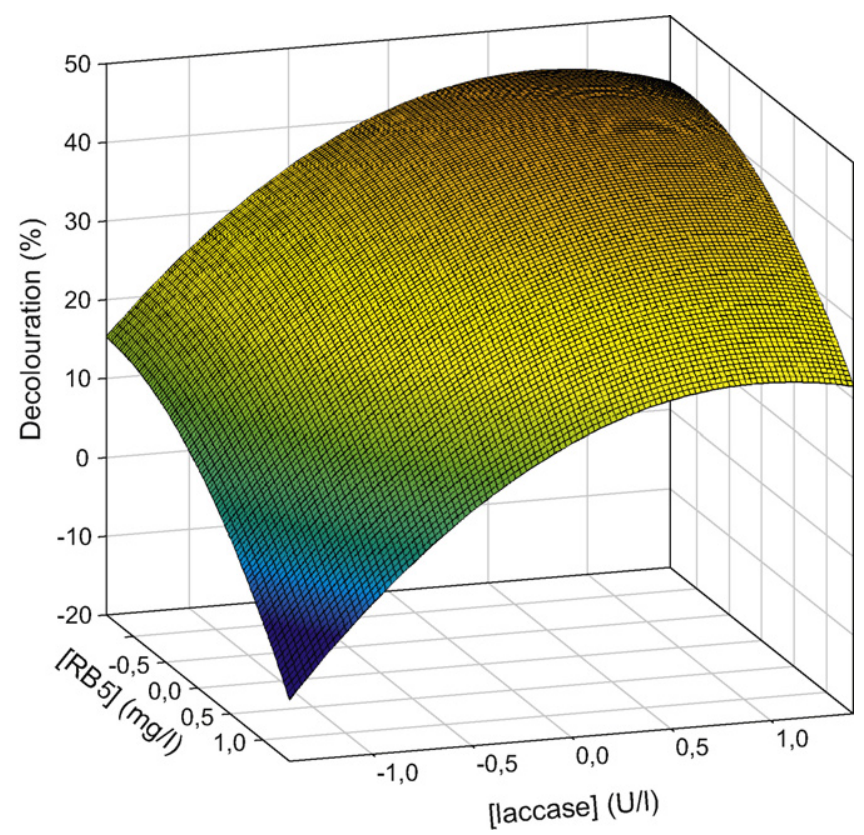

Fig. 4. 3D surface plot for the removal of Reactive Black 5 (RB5) by laccase as a function of dye and enzyme concentrations at a fixed value of $0.75 \mathrm{mM} \mathrm{1-}$ hydroxybenzotriazole (HBT).

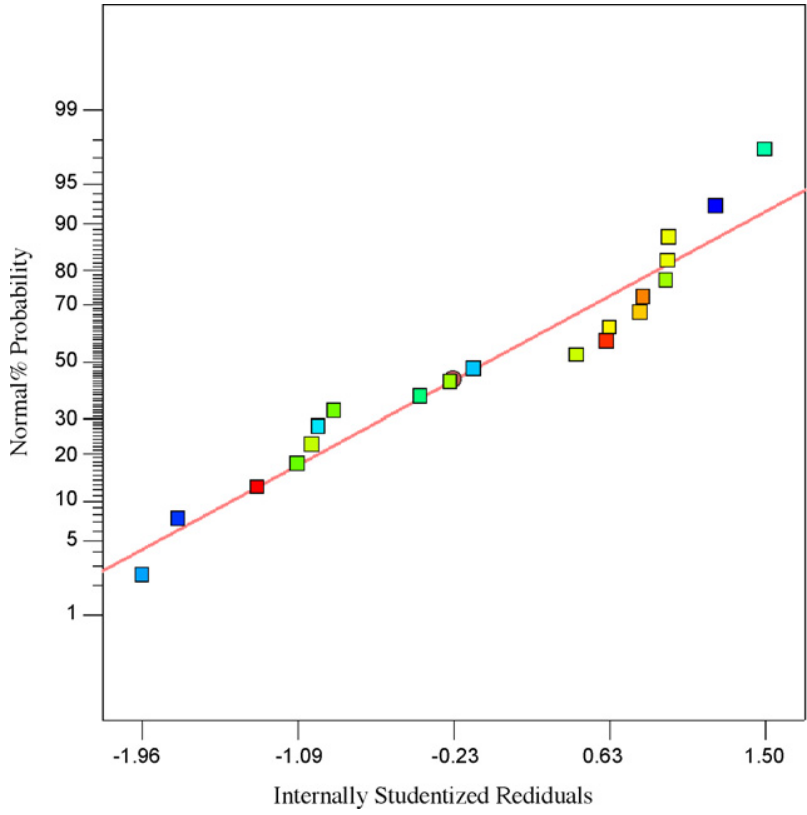

Fig. 5. Studentised plot showing normal \% probability versus internally studentised residuals.

the fit of a model [11]. In the present model, $R^{2}$ was adjudged to be 0.965 , which indicates the fitness of the model. For further validation of the model, adjusted $R^{2}$ was used for confirming the model adequacy. The adjusted $R^{2}$ was calculated to be 0.948 , which indicates a good model for using in the field conditions. The residual analysis was also carried out for judging the model adequacy. A rough check of the outliers was performed by examining the internally studentised residuals. The residuals should be approximately normal with mean zero and unit variance [11]. It was observed that none of the studentised residuals had a value higher than 2 (Fig. 5). To validate the model further and check the outliers, the externally studentised residuals were calculated (Table 3 ). All the values lie within the range of -2 and +2 (values between -3 and +3 being the acceptable limit), thereby validating the model.

\subsection{Kinetic study}

Fig. 6 shows the kinetics of RB5 decolouration by crude laccase form $T$. pubescens corresponding to different initial dye concen-

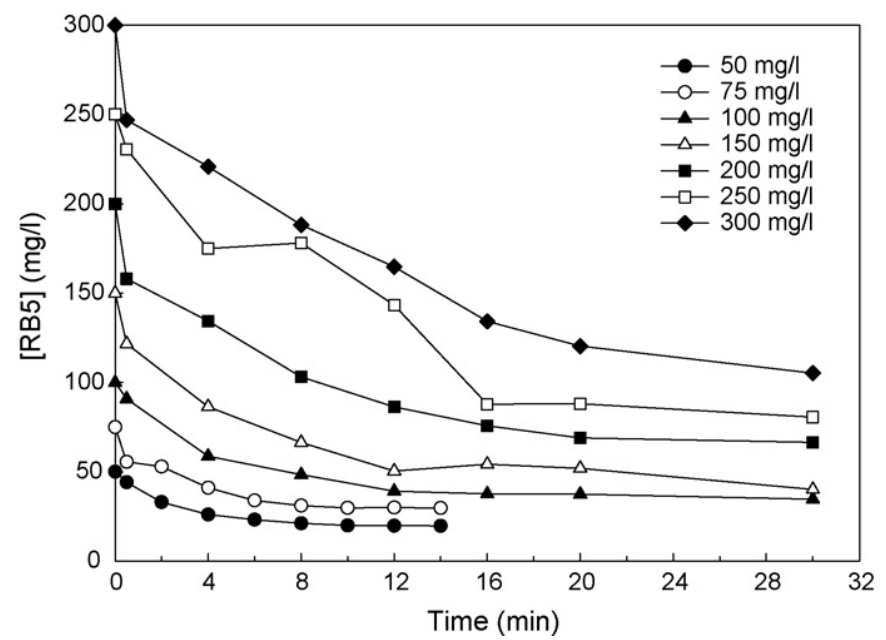

Fig. 6. The residual concentration of Reactive Black 5 (RB5) along time for different initial dye concentrations. 


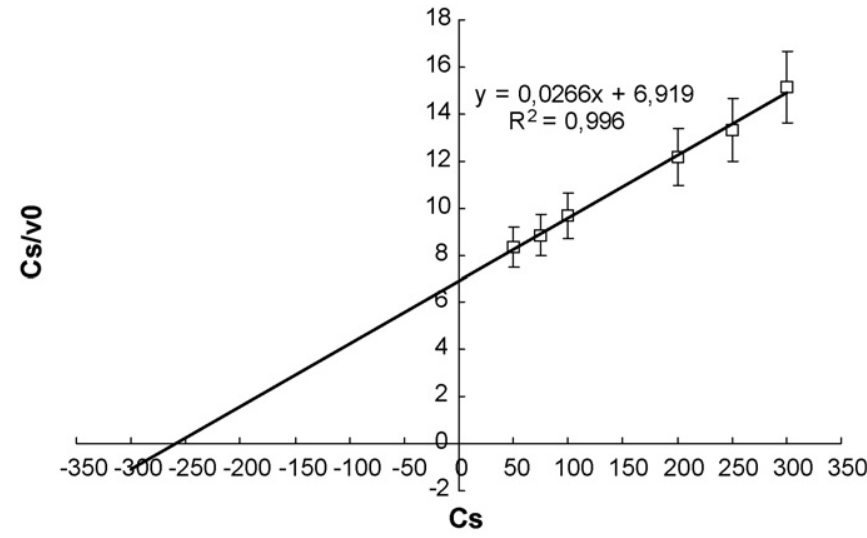

Fig. 7. Hanes-Wolf plot of the kinetics of Reactive Black 5 (RB5) decolouration.

trations. The kinetic parameters of RB5 decolouration by laccase $\left(K_{\mathrm{M}}\right.$ and $V_{\max }$ ) were estimated from Hannes-Wolf plot as shown in Fig. 7. The Hannes-Wolf plot gave a $K_{\mathrm{M}}$ of $260.11 \mathrm{mg} / \mathrm{l}$ and $V_{\max }$ of $37.59 \mathrm{mg} / \mathrm{l} \mathrm{min}$ for the diazo dye RB5 decolouration by laccase. The high $K_{\mathrm{M}}$ value suggests that RB5 is not susceptible to laccase attack which confirms the necessity of a redox mediator for RB5 decolouration by laccase. The $K_{\mathrm{M}}$ value was almost 3-fold higher and $V_{\max }$ about 500 -fold higher than those obtained by Mazmanci and Ünyayar [30] for cultures of Funalia trogii immobilised on Luffa cylindrica. So, enzyme systems seem very promising for dye decolouration.

\section{Conclusions}

Crude laccase enzyme was used as a biocatalyst for the decolouration of the diazo dye Reactive Black 5. Response surface methodology (RSM) was successfully applied to determine the optimal operational conditions for maximum decolouration, which were found to be $150 \mathrm{mg} / \mathrm{l} \mathrm{RB} 5,1.17 \mathrm{mM} \mathrm{HBT}$ and $500 \mathrm{U} / \mathrm{l}$ laccase. A quadratic model, developed in terms of HBT, RB5 and laccase concentrations, to represent the decolouration percentage and the corresponding coefficients of independent variables was estimated by the application of Design Expert 7.1 trial version. Also, the kinetic parameters of RB5 decolouration by crude laccase were determined. The reaction kinetic fitted well to the Michaelis Menten model and $K_{\mathrm{M}}$ of $260.11 \mathrm{mg} / \mathrm{l}$ and $V_{\max }$ of $37.59 \mathrm{mg} / \mathrm{l} \mathrm{min} \mathrm{were} \mathrm{found.}$

\section{Acknowledgements}

This research was financed by the Spanish Ministry of Education and Science (Project CTQ2007-66541). The authors would like to express their sincere thanks to Prof. Dr. José L. Toca Herrera for the kind lending of the UV-Visible spectrophotometer Helios alfa (Thermo Spectronic, Cambridge, UK). SRC is a Ramón y Cajal Senior Research Fellow and gratefully acknowledges the Spanish Ministry of Education and Science for promoting the Ramón y Cajal Programme and the European Social Fund for co-financing her contract. MR acknowledges the Erasmus mobility programme. JFO is supported by a pre-doctoral fellowship from the Rovira i Virgili University (Tarragona, Spain).

\section{References}

[1] G. Palmieri, G. Cennamo, G. Sannia, Remazol Brilliant R decolourisation by the fungus Pleurotus ostreatus and its oxidative enzymatic system, Enzyme Microb. Technol. 36 (2005) 17-27.
[2] L. Levin, L. Papinutti, F. Forchiassin, Evaluation of Argentinean white rot fungi for their ability to produce lignin-modifying enzymes and decolorize industrial dyes, Biores. Technol. 94 (2004) 169-176.

[3] R.L.M. Allen, The chemistry of azo dyes, in: Colour Chemistry, AppletonCentury-Crofts, New York, 1971.

[4] A.A. Dias, M.R. Bezerra, M.P. Lemos, N.A. Pereira, In vivo and lacasse catalysed decolorization of xenobiotic azo dyes by a basidiomycetous fungus: characterization of its ligninolytic system, World J. Microb. Biotechnol. 19 (2003) 969-975.

[5] T. Mechichi, N. Mhiri, S. Sayadi, Brilliant Blue R decolorization by the laccase from Trametes trogii, Chemosphere 64 (2006) 998-1005.

[6] P. Moller, H. Wallin, Genotoxic hazards of azo pigments and other colorants related to 1-phenylazo-2-hydroxynaphthalene, Mutat. Res. 462 (2000) 13-30.

[7] P. Nigam, I.M. Banat, D. Singh, R. Marchant, Microbial process for the decolorization of textile effluent containing azo, diazo and reactive dyes, Process Biochem. 31 (1996) 435-442.

[8] N. Durán, E. Esposito, Potential applications of oxidative enzymes and phenoloxidase-like compounds in wastewater and soil treatment: a review, Appl. Catal. B: Environ. 28 (2000) 83-99.

[9] M.A. McGuirl, D.M. Dooley, Copper-containing oxidases, Curr. Opin. Chem. Biol. 3 (1999) 138-144.

[10] Y. Wong, J. Yu, Laccase-catalyzed decolorization of synthetic dyes, Water Res. 33 (1999) 3512-4352.

[11] R.H. Myers, D.C. Montgomery, Response Surface Methodology, John Wiley \& Sons, Inc., USA, 2002.

[12] H. Ceylan, S. Kubilay, N. Aktas, N. Sahiner, An approach for prediction of optimum reaction conditions for laccase-catalyzed bio-transformation of 1naphthol by response surface methodology (RSM), Biores. Technol. 99 (2008) 2025-2031.

[13] C. Galhaup, D. Haltrich, Enhanced formation of laccase activity by the white-rot fungus Trametes pubescens in the presence of copper, Appl. Microbiol. Biotechnol. 56 (2001) 225-232.

[14] C. Galhaup, H. Wagner, B. Hintertoisser, D. Haltrich, Increased production of laccase by the wood-degrading basidiomycete Trametes pubescens, Enzyme Microb. Technol. 30 (2002) 529-536.

[15] S. Rodríguez Couto, J. Osma, J.L. Toca Herrera, Removal of synthetic dyes by an eco-friendly strategy, Eng. Life Sci. 9 (2009) 116-123.

[16] M.L. Niku-Paavola, L. Raaska, M. Itävaara, Detection of white-rot fungi by a nontoxic stain, Mycol. Res. 94 (1990) 27-31.

[17] M. Mohorčič, J. Friedrich, A. Pavko, Decoloration of the diazo dye reactive black 5 by immobilised Bjerkandera adusta in a stirred tank bioreactor, Acta Chim. Slov. 51 (2004) 619-628.

[18] D.C. Shrama, T. Satyanarayan, A marked enhancement in the production of a highly alkaline and thermostable pectinase by Bacillus pumilus dcsr 1 in submerged fermentation by using statistical methods, Biores. Technol. 97 (2006) 727-733.

[19] K. Enayatzamir, H.A. Alikhani, S. Rodríguez Couto, Simultaneous production of laccase and decolouration of the diazo dye Reactive Black 5 in a fixed-bed bioreactor, J. Hazard. Mater. 164 (2009) 296-300.

[20] S. Rodríguez Couto, M.A. Sanromán, G.M. Gübitz, Influence of redox mediators and metal ions on synthetic acid dye decolourization by crude laccase from Trametes hirsuta, Chemosphere 58 (2005) 417-422.

[21] M. Elibol, Optimization of medium composition for actinorhodin production by Streptomyces coelicolor A3(2) with response surface methodology, Process Biochem. 39 (2004) 1057-1062.

[22] H. Claus, G. Faber, H. König, Redox-mediated decolorization of synthetic dyes by fungal laccases, Appl. Microbiol. Biotechnol. 59 (2002) 672-678.

[23] G.S. Nyanhongo, J. Gomes, G.M. Gübitz, R. Zvauya, J. Read, W. Steiner, Decolorization of textile dyes by laccases from a newly isolated strain of Trametes modesta, Water Res. 36 (2002) 1449-1456.

[24] S. Camarero, D. Ibarra, M.J. Martínez, A.T. Martínez, Lignin-derived compounds as efficient laccase mediators for decolorization of different types of recalcitrant dyes, Appl. Environ. Microbiol. 71 (2005) 1775-1784.

[25] A.P.M. Tavares, R.O. Cristóvão, J.M. Loureiro, R.A.R. Boaventura, E.A. Macedo, Optimisation of reactive textile dyes degradation by laccase-mediator system, J. Chem. Technol. Biotechnol. 83 (2008) 1609-1615.

[26] K. Murugesan, A. Dhamija, I.H. Nam, Y.M. Kim, Y.S. Chang, Decolourization of reactive black 5 by laccase: optimization by response surface methodology, Dyes Pigments 75 (2007) 176-184.

[27] V. Kokol, A. Doliska, I. Eichlerova, P. Baldrian, F. Nerud, Decolorization of textile dyes by whole cultures of Ischnoderma resinosum and by purified laccase and Mn-peroxidase, Enzyme Microb. Technol. 40 (2006) 1673-1677.

[28] O. García, S. Camarero, J. Colom, A.T. Martínez, M.J. Martínez, R. Monje, T. Vidal, Optimization of a laccase-mediator stage for TCF bleaching of flax pulp, Holzforschung 57 (2003) 513-519.

[29] R.O. Cristóvão, A.P.M. Tavares, A.S. Ribeiro, J.M. Loureiro, R.A.R. Boaventura, E.A. Macedo, Kinetic modelling and simulation of laccase catalyzed degradation of reactive textile dyes, Biores. Technol. 99 (2008) 4768-4774.

[30] M.A. Mazmanci, A. Unyayar, Decolourisation of Reactive Black 5 by Funalia trogii immobilised on Luffa cylindrica sponge, Process Biochem. 40 (2005) 337 342. 